\title{
Beyond the Handbook: The Influence of L1 in the Language Classroom*
}

\author{
Nancy Mae Antrim*
}

Sul Ross State University, USA

\begin{abstract}
Many handbooks of English grammar (Heath Handbook, The Bedford Handbook for Writers, various editions) include a section for ESL problems. The two major areas that are addressed involve the use of articles and verbal forms and tenses. While these are critical areas of grammar that are problematic for ESL students, there are a number of other areas that influence ESL student writing that are not addressed. Drawing on written work submitted by Spanish dominant speakers enrolled in university level English classes, this paper explores areas that contribute to inappropriate word choices by non-native speakers writing in English. ESL teachers need to be aware of the underlying reasons for inappropriate word choices and spelling errors made by these Spanish speaking students in order to better address these problem areas. This paper addresses only four (pronunciation, connectors, prepositions, and verbal expressions) in an effort to expand on the limited discussion of ESL problems addressed in a variety of grammar/writing handbooks, if in fact the handbooks do contain an ESL section.
\end{abstract}

*I would like to thank the participants at the Oxford Roundtable on Bilingual Education (2001) and the anonymous reviewers for their comments and suggestions. All errors remain my own.

\section{INTRODUCTION}

Various researchers have defined interference. Dulay, Burt, and Krashen [1] define interference as an automatic transfer of the surface structure from the first language to the target language. While Dulay et al. [1] attribute this to habit, Lot [2] refers to interference as errors in the second language that come from the first language. Ellis [3] views interference as transfer, but sees it as a more conscious process on the part of the learner. Using the structures from their first language, the learner hypothesizes what may be transferable. Ellis [3] further draws a distinction between errors and mistakes, attributing errors to gaps in the learner's knowledge of the target language, while mistakes are related to performance.

Dechert [4] suggests that interference is a strategy used by the learner to predict equivalences between the two languages involved. This may explain, in part, lexical interference, as argued by Albert and Obler [5]. Beardsmore [6], along the lines of Dulay et al. [1] views interference as habits from the first language expanding on vocabulary to include phonology and grammar.

Whether it is habit or conscious strategy, the transfer of first language structures to the target language is an observable phenomenon in the language classroom.

Weinreich [7], in one of the first works on language interference, observes three areas in which first language may interfere in the second language: phonic/phonological, lexical and syntactic. He argues that interference is to be expected in any situation where languages come into contact. Second language learning, whether natural or in the classroom, provides just such a situation. The advantage in a bilingual classroom is that we are dealing with only two lan-

*Address correspondence to this author at the Sul Ross State University, USA; Tel: 432-837-8152; Fax: 432-837-8714; E-mail: nantrim@sulross.edu guages, whereas in an ESL classroom multiple languages may be involved. However, even in the bilingual classroom, multiple dialects of the first language may be present.

While we expect bilingual teachers to be trained in both languages, this is often not the case. The assumption being that they speak the first language of their students and that that is sufficient. This is also a common misconception with respect to ESL teachers as well. While they are not expected to know all the languages of their students, speaking English is considered not only necessary, but sufficient. This lack of language/linguistic preparation results in a reliance on textbooks, grammars and handbooks.

Many handbooks of English grammar (Heath Handbook, The Bedford Handbook for Writers, various editions) include a section for ESL problems. The two major areas that are addressed involve the use of articles and verbal forms and tenses. While these are critical areas of grammar that are problematic for ESL students, there are a number of other areas that influence ESL student writing that are not addressed. Drawing on written work submitted by Spanish dominant speakers enrolled in university level English classes, this paper explores four areas that contribute to inappropriate word choices by non-native speakers writing in English: pronunciation, connectors, prepositions, and verbal expressions.

\section{PRONUNCIATION}

While handbooks often include lists of homophones that are problematic for both native and non-native writers, spelling errors and word choices are also influenced by the students' pronunciation of English words. What is often viewed as a grammatical error, such as subject-verb agreement, may be the student's spelling the word as pronounced. For example, the vowel in "this" would be pronounced in Spanish to sound like the English word "these" resulting in the student writing "this books." In addition to spelling English words 
phonetically as it would be represented in Spanish, Spanish vowels may be substituted for English vowels that are not present in Spanish. In the inventory of Spanish phonemes there is no /I/, the lax, high front vowel found in English., resulting in confusion between words such as 'he's and his', both written as 'hes,' although the student may acknowledge the difference between the possessive and the contraction by employing the apostrophe, so that we have 'hes' for 'his' but added apostrophe for 'he's', as reported by Garcia [8]. This substitution of Spanish phonemes in English words is not limited to vowels; consonants may also be affected. Here we find such substitutions as 'hands' /hændz/ being produced for 'hangs' /hæyz/.

There are a number of contrasts in English that prove problematic for speakers of other languages. English vowel contrasts are difficult for Spanish speakers, since English makes more vocalic distinctions than Spanish does. The tense/lax contrast found in English is not used in Spanish, resulting in difficulties with such words as 'beat' and 'bit,' 'pool' and 'pull,' 'boat' and 'bought,' and 'cat,' 'cot,' and 'cut' [9].

Spanish also proves to be more phonotacically restrictive than English. Whitely [9] observes three restrictions in Spanish that may result in difficulties for the Spanish speaker learning English. The only consonants commonly occurring at the end of words in Spanish are the coronals /d, s, n, r, 1, $\theta /$. English does not have this restraint. This may account for misspellings such as 'shards' for 'charts.'

Permissible consonant clusters differ between English and Spanish. Words in Spanish are not permitted to end in clusters of two or more consonants, but this occurs frequently in English (i.e. sixths, glimpsed). Spanish speakers will often lose all but one of these consonants or add a vowel to create an additional syllable in their pronunciation of these words. This pronunciation is then reflected in their spellings.

Spanish does not permit the cluster ' $\mathrm{s} C$ ' word initial. Spanish speakers in learning English will insert an initial vowel in order to break up the English cluster ' $\mathrm{sC}$.' This results in the production of 'eschool' for school and this pronunciation may also be transferred to writing. A beginning ESL student when playing hangman had seven blanks indicated for her word; after guessing several of the letters ( _ hool), the class was stumped. The word she wanted was 'school' which she was spelling as 'eschool.'

Finally, homographs and homophones are also problematic for ESL students. In a student response, one student wrote that he was 'board' instead of 'bored.' Homographs such as 'read' and 'read' show up in student writing as 'read' and 'red.' Confusion between 'rear' and 'rare' resulted in one student writing "very rear as a family."

\section{CONNECTORS}

Word choice may also be influenced by the lexical relationships expressed by connectors (e.g. so, and, but) that differ in Spanish and English. For example, English 'but' applies to three distinct Spanish relations: menos (exception to or subtraction from (everyone but Maria); pero with mas (opposed consideration (but on the other hand); sino (cancels what precedes (but instead).
'So' has several functions in English ranging from degree to conjunction, as well as, its use in spoken discourse. These functions, shown in (1), include:

1. a. He's so smart. (degree)

b. And he so did it. (proform of manner)

c. Is John coming? I think so. (proform of a proposition)

d. He missed the exam, so he failed the course. (conjunction)

Each of these functions has a different expression in Spanish; for degree Spanish would use 'tan;' for an adverbial proform, Spanish uses 'asi;' as a proform for a proposition, Spanish employs 'que;' and as a conjunction, Spanish uses 'asi que.'

With respect to spoken discourse, 'so' in English is used at the beginning of sentences and as a connector in run-on sentences. Shaw and Liu [10] reported a decline in the use of "so," a typically spoken and rather vague connector, in their study of register features in non-NSE writing. They interpreted this to indicate an increase in better defined logical relations. Examining the English writing of 60 university level Spanish-speaking ESL students ranging from beginners to advanced, Antrim [11] analyzed their writing for evidence of the development of English rhetorical features. Antrim [11] found that Spanish speaking ESL students tended to rely on the spoken discourse function of 'so' in their writing. This use of the connector "so" supports the influence of Spanish rhetorical features where sentences tend to be loosely connected. Antrim [11] did not find a decrease in the use of "so"; instead the use of "so" rose from less than $1 \%$ in the beginner group to $9 \%$ in the advanced group. This suggests a preference for "loose coordination" as observed by Reid [12], a characteristic of Spanish rhetoric rather than English.

On closer examination the use of "so" may reflect the development of the students' spoken language. Over half the cases of "so" in the intermediate group occurred in environments analogous to the use of "so" in spoken discourse: at the beginning of a sentence and as a connector in run-on sentences. There was a slight decline of "so" use in these environments with the advanced group. The beginning group had only one instance of "so" use within a run-on sentence and none as sentence initial providing a misleading $100 \%$ usage of "so" in environments consistent with spoken language. Clearly the use of "so" increases with the increase in spoken language proficiency and reflects spoken language rather than English written discourse. [11]

Table 1. Use of "so"

\begin{tabular}{|c|c|c|c|}
\hline Group & Beginner & Intermediate & Advanced \\
\hline \hline Total & 1 & 30 & 26 \\
\hline Sentence Initial & 0 & 1 & 4 \\
\hline Run-on Sentences & 0 & 16 & 8 \\
\hline Percentage & $100 \%$ & $57 \%$ & $46 \%$ \\
\hline
\end{tabular}




\section{PREPOSITIONS}

Prepositional relationships are also problematic for the Spanish speaker since the prepositional content varies between languages. Spanish uses three prepositions to express a variety of prepositional relationships in English: English 'in, on, at' for location; 'into, onto, to' for direction and 'out of, off (of), from' for origin as opposed to Spanish 'en' (in, on, into, onto), 'a' (at, to), and 'de' (out of, off (of), from). Tables two and three illustrate these relationships. [9]

Table 2. English Prepositions

\begin{tabular}{|c|c|c|c|}
\hline & enclosure & contact & adjacency \\
\hline \hline location & in & on & at \\
\hline direction & into & onto & to \\
\hline origin & out of & off(of) & from \\
\hline
\end{tabular}

Table 3. Spanish Prepositions

\begin{tabular}{|c|c|c|c|}
\hline & enclosure & contact & adjacency \\
\hline \hline location & en & en & a \\
\hline direction & en & en & a \\
\hline origin & de & de & de \\
\hline
\end{tabular}

'In' and 'on' are particularly difficult for Spanish speaking students since both of these relationships are represented by the single preposition 'en' in Spanish, resulting in students writing 'in the weekend.' Since the preposition 'at' is expressed by the same preposition as English 'to' by the Spanish 'a', we find students writing 'at the United States.'

\section{VERBAL EXPRESSIONS}

Verb forms involving prepositions and particles also differ. Spanish lacks two-word verbs and the category of verb particle. Verbs vary with respect to whether they require a preposition. In Spanish, the preposition may be incorporated into the verb and the addition of the preposition is both redundant and ungrammatical, as seen in the following example. The Spanish verb 'escuchar' does not require a preposition whereas the English verb 'listen' may take a preposition. This difference between verbal forms results in students producing such sentences as shown in (2a). Likewise, Spanish verbs may require a preposition where one is not required in the English counterpart resulting in ungrammatical sentences such as 2(b). To change clothes, 'cambiar de,' in Spanish requires the preposition 'de,' while English does not.

2. a. *I listen the music.

b. *I change of the clothes.

c. Contar con $\neq$ rely with

Even when both languages employ a preposition with a verb, the prepositions may not be equivalent, as in (2c). See Whitley [9] for discussion and lists of verbs in both Spanish and English with the appropriate preposition.
Expressions of verbs of manner, direction, and result vary between English and Spanish. English employs verbs of manner with an adverbial of direction; whereas, Spanish utilizes a verb of direction with an adverbial of manner, as shown in (3a). English also shows a preference for verbs of manner with result adverbials; whereas, Spanish prefers an adverbial of manner with a result verb, as seen in (3b).

$\begin{array}{llll}\text { 3. a. English: } & \begin{array}{l}\text { Everyone } \\ \text { drove away. } \\ \text { V of manner } \\ \text { + direction }\end{array} & \text { Spanish: } & \begin{array}{l}\text { Todos se fueron en coche } \\ \text { Everyone went by car. }\end{array} \\ \text { b. English: } & \begin{array}{l}\text { She slammed } \\ \text { the door shut. }\end{array} & \text { Spanish: } \\ & \text { V of manner } \\ + \text { result } & & \begin{array}{l}\text { Cerro la puerta de un } \\ \text { golpe. }\end{array} \\ & & \begin{array}{l}\text { She closed the door with a } \\ \text { bang. }\end{array} \\ & & \text { V of result + manner }\end{array}$

Whitley and González [13] cite the frequency of the expression of movement, manner, and result in narratives as reason for these contrasts to be pointed out to students.

\section{CONCLUSION}

"Language can interact and affect the learning of each other on various levels. They also prove that predictions of learner progression are extremely difficult, and interactions often depend on learner niveau, the language constellation involved, the area of language being examined, and numerous other factors [14]".

The interference of the first language in the acquisition of the second has been clearly documented. Aronin and Tonbkin [15] extend this interference to the acquisition of a third language in their study of the relationship between L1, L2, and L3 for Russian-speaking students in Israeli immersion programs.

While the increasing number of Spanish speakers in the schools, and not just the school districts along the Mexican/American border, ESL teachers need to be aware of the underlying reasons for inappropriate word choices and spelling errors by these Spanish speaking students. While the examples are based on Spanish speaking ESL students, these areas are problematic for ESL students with differ first languages and the conclusions drawn can be applied for these students as well. What remains crucial is the need for ESL instructors to be aware of the areas of grammar that vary between the students' first languages and English. While contrastive grammar and contrastive rhetoric (an area that must remain for another time) have fallen into disrepute and been discarded as viable explanations for student acquisition of a second language, they have much to say for the ESL classroom as a means to explain English grammar as well as those student errors that stem from the influence of their first language.

The structure and types of errors made in the student's second language can be beneficial to both the teaching and learning processes by providing a foundation for the development of individualized learning plans for each student. Knowledge of the grammars of both languages, L1 and L2, and the possible areas of transfer and interference will enable the teacher to predict possible errors in the target language. 
In noting the frequency of types of errors, the teacher will be better able to develop and adjust teaching techniques to improve student success in acquiring the target language.

This paper addresses only four (pronunciation, connectors, prepositions, and verbal expressions) areas of interference in an effort to expand on the limited discussion of ESL problems addressed in a variety of grammar/writing handbooks, if in fact the handbooks do contain an ESL section and provide support for expanding teacher preparation to include contrastive grammar.

\section{REFERENCES}

[1] Dulay H, Burt M, Krashen S. Language Two. New York: Oxford University Press 1982.

[2] Lott D. Analyzing and counteracting interlanguage errors. ELT J 1983; 37: 3: 256-61.

[3] Ellis R. Second Language Acquisition. Oxford: Oxford University Press 1997.

[4] Dechert HW. How a story is done in a second language in Strategies. In Faerch C, Kasper G Eds. Interlanguage Communications, London: Longman 1983; pp.175-95.

[5] Albert ML, Obler LK. The Bilingual Brain: Neuropsychological and Neurolinguistic Aspects of Bilingualism. New York: Academic Press 1978.

[6] Beardsmore HB. Bilingualism: Basic Principles. Avon: Tieto 1982.
[7] Weinreich U. Languages in Contact. New York: Linguistic Circles of New York 1953.

[8] Garcia R. A Linguistic Frame of Reference for Critiquing Chicano Compositions. In: Oaks D Ed. Linguistics at Work, Cambridge, MA: Heinle \& Heinle 2001: pp. 184-88.

[9] Whitley MS. Spanish/English Contrasts. Washington D.C.: Georgetown University Press 2002.

[10] Shaw P, Ting-Kun Liu E. What develops in the development of a second-language writing? Applied Linguistics 1998; 19/2: 225-54.

[11] Antrim NM. Developing an L2 Rhetoric. In Zybatow L, Ed. Europa der Sprachen: Sprachkompetenz-Mehrsprachigkeit-Translation. Vol. 2: Sprache und Kognition.Frankfurt, Germany, Peter Lang 2003; pp. 435-44.

[12] Reid J. Quantitative differences in English prose written by Arabic, Chinese, Spanish, and English students. Ph.D. [Dissertation], Mount Pleasant (MI): Colorado State University, 1988.

[13] Whitely MS, González L. Gramática para la composición. Washington D.C.: Georgetown University Press 2000.

[14] Marx N. Conclusion: Looking beyond and looking forward. In: Cenoz J, Hufeisen B, Jessner U Eds. Looking Beyond Second Language Acquisition: Studies in Tri- and Multilingualism, Tübingen: Stauffenburg 2001: pp. 153-60.

[15] Aronin L, Toubkin L. Language Interference and Language Learning Techniques Transfer in L2 and L3 Immersion Programmes. International Journal of Bilingual Education and Bilingualism 2002; 5: $5,267-78$

(C) Nancy Mae Antrim; Licensee Bentham Open.

This is an open access article distributed under the terms of the Creative Commons Attribution License (http://creativecommons.org/licenses/by/2.5/), which permits unrestrictive use, distribution, and reproduction in any medium, provided the original work is properly cited. 